\title{
O OUVINTE E A MESA-REDONDA ESPORTIVA NO RÁDIO: uma extensão do "papo de bar"
} THE LISTENER AND THE SPORTS ROUNDTABLE ON THE RADIO: an extension of the "bar talk

\author{
Carlos GUIMARÃES ${ }^{1}$ \\ Pontifícia Universidade Católica do Rio Grande do Sul | Brasil
}

\begin{abstract}
Resumo
O artigo pretende analisar o comportamento dos ouvintes de quatro programas de mesa redonda no rádio esportivo de Porto Alegre a partir da participação deles em fóruns de discussão. Estes espaços são a área de comentários do Facebook durante a realização dos debates. Considera-se a hipótese de que estes fóruns operam como uma continuidade do que é discutido nos programas. Situa-se teoricamente a partir de conceber o rádio sendo, em primeiro momento, um companheiro (BRECHT, 2000) e uma extensão de sentidos do homem (McLUHAN, 1964). Pretende-se observar a ação do ouvinte nesta relação, entendendo-o como um agente de produção no conteúdo radiofônico através do seu agir comunicativo (HABERMAS, 1981) e do papel assumido por ele neste ambiente (GOFFMAN, 2014). Para analisar esse material, utiliza-se a análise de conteúdo (BARDIN, 2016) como metodologia principal.

Palavras-chave

Rádio; Jornalismo Esportivo; Redes Sociais; Audiência; Mesa-redonda esportiva.

\section{Abstract}

The article intends to analyze the behavior of listeners of four "roundtable" programs on sports radio in Porto Alegre based on their participation in discussion forums. These spaces are the Facebook comments area during the debates. It is assumed that these forums operate as a continuation of what is discussed in the programs. It is theoretically situated from the conception of the radio, being, in the first moment, a companion (BRECHT, 2000) and an extension of man's senses (MCLUHAN, 1964). It is intended to observe the action of the listener in this relationship, understanding him as a production agent in radio content through his communicative action (HABERMAS, 1981) and the role he assumed in this environment (GOFFMAN, 2014). To analyze this material, content analysis (BARDIN, 2016) is used as the main methodology.

\section{Keywords}

Radio; Sports Journalism; Social Network; Audience; Sports Roundtable.
\end{abstract}

RECEBIDO EM 02 DE ABRIL DE 2020

ACEITO EM 11 DE MAIO DE 2020

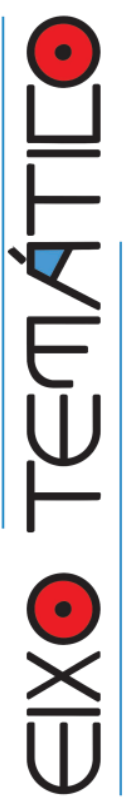

${ }^{1}$ Doutorando em Comunicação pelo Programa de Pós-Graduação da Faculdade de Comunicação e Design (FAMECOS), da Pontifícia Universidade Católica do Rio Grande do Sul (PUCRS). Mestre em Comunicação e Informação pela Universidade Federal do Rio Grande do Sul (UFRGS). Contato: csguimaraes@gmail.com

João Pessoa - Brasil | ANO 7 VOL.7 N.1 | JAN./JUN. 2020 | p. 322-341 


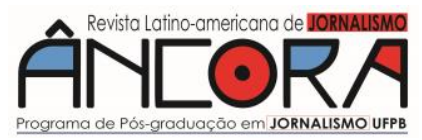

Carlos GUIMARÃES

\section{Introdução}

eis pessoas conversam sobre futebol. Estão dispostas em torno de uma 3. mesa, com um microfone para cada integrante do debate. Essa conversa é transmitida pelo rádio. Falam sobre os assuntos mais relevantes que o esporte apresentou no final de semana, como, por exemplo, a rodada do Campeonato Brasileiro e o título do Flamengo na Copa Libertadores da América de 2019. A troca de opiniões obedece a uma pauta, a uma lógica de assuntos e a uma linha de edição que, por duas horas, norteia os integrantes do programa. Trata-se de uma mesa-redonda ${ }^{2}$ no rádio, formato consagrado nas programações das emissoras de rádio brasileiras que cobrem futebol.

Ferraretto (2014, p.74) define a mesa-redonda como um tipo de programa, constituído pela opinião de convidados ou participantes que se aprofundam em temas da atualidade, interpretando-os. Quando o tema é o futebol, é preciso salientar que o jornalismo esportivo tem, em sua base, uma independência em forma e conteúdo, por conta de editorias especializadas no assunto tratarem o futebol com certa frouxidão nos rigores jornalísticos (AMARAL, 1969; MARQUES DE MELO, 2003; OSELAME, 2012). Os programas esportivos, em uma grade de informação, também se diferenciam em suas abordagens. Ao contrário dos tradicionais programas informativos, o formato de mesa-redonda permite um relaxamento maior dos integrantes da bancada, especialmente por conta de como a trajetória deste tipo de programa foi construída no rádio informativo.

A partir da fase de convergência do rádio brasileiro (FERRARETTO, 2012), as emissoras adotaram como estratégia expandir suas transmissões para outras plataformas. Com o impacto das redes sociais na comunicação contemporânea, é natural que o conteúdo apresentado outrora apenas em

${ }^{2}$ Conforme o Dicionário Houaiss (2015, p.634), o vocábulo mesa-redonda é um substantivo feminino, escrito com hífen e que representa uma conferência em que todos os participantes têm igual importância.

João Pessoa - Brasil | ANO 7 VOL.7 N.1 | JAN./JUN. 2020 | p. 322-341 
modalidade radiofônica tenha um transbordamento para outros meios. Redes como o Facebook e o YouTube, por exemplo, permitem a visualização do programa, como se fosse uma transmissão pela televisão. Remete-se ao conceito de segunda tela, originalmente empregado para o conteúdo televisivo, em que "um equipamento ligado à Internet é utilizado pelo telespectador simultaneamente à programação de televisão numa navegação influenciada pelo conteúdo exibido" (CANATTA, 2014, p.74). Aplica-se, portanto, este conceito ao rádio: enquanto a programação é transmitida normalmente pelas ondas hertzianas ou por dispositivos na internet ${ }^{3}$, as emissoras de rádio disponibilizam canais onde é possível assistir aos programas e, por conta da arquitetura de redes sociais como o Facebook e o Youtube, permite-se comentar sobre o que é dito pelos comunicadores, ou mesmo promover debates paralelos nos fóruns dedicados às opiniões dos ouvintes.

A proposta do artigo é analisar o comportamento dos ouvintes nestes fóruns de discussão no Facebook enquanto ocorre, simultaneamente, a realização de quatro mesas-redondas no rádio esportivo de Porto Alegre. 0 recorte se aplica aos programas Dupla em Debate, da Rádio Grenal; Ganhando o Jogo, da Rádio Guaíba; Sala de Redação, da Rádio Gaúcha e Toque de Bola, da Rádio Bandeirantes. A hipótese é que estes comportamentos se manifestam como uma extensão do que é transmitido, ou seja, o ouvinte sente-se pertencido, acolhido e atuante. $O$ fluxo de opiniões no fórum atende à mesma dinâmica do conteúdo transmitido, como se houvesse um debate expandido entre os participantes destes espaços de comentários. A rede social analisada é o Facebook durante a transmissão das lives ${ }^{4}$ disponibilizadas pelas emissoras. Aplica-se a análise de conteúdo como metodologia principal, seguindo as recomendações de Bardin (2016), a partir de um referencial teórico a respeito da função do rádio como companheiro (BRECHT, 2000), do que é uma mesa-

\footnotetext{
3 Trata-se de uma referência às rádios web, apoiando-se teoricamente nos conceitos de rádio expandido (KISCHINHEVS KY, 2011) e rádio hipermidiático (LOPEZ, 2010), em que o rádio opera além das ondas hertzianas, com o conteúdo de áudio repassado através de plataformas disponíveis por conexões digitais. ${ }^{4}$ Momento em que acontece a segunda tela, isto é, enquanto o programa é transmitido pelo rádio, pode ser visto pela rede social, com a possibilidade do ouvinte comentá-lo durante a transmissão.
} 


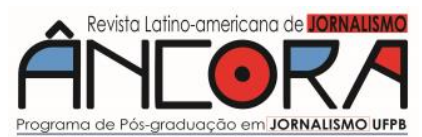

Carlos GUIMARÃES

redonda no rádio (AMARAL; FERRARETTO, 2014; MARQUES DE MELO, 2003), de como funciona esse sentido de extensão para o ouvinte (McLUHAN, 1964), de que maneira quem recebe - a audiência - se torna agente de emissão (ENZENSBERGER, 1979; HABERMAS, 1981) e, por fim, de como se dá o comportamento do receptor em ambientes de esfera pública ${ }^{5}$, com as observações propostas por Goffman (2010).

\section{A dinâmica da mesa redonda esportiva: a falação no horário do almoço}

A mesa-redonda esportiva permite uma abordagem menos engessada e formal que um debate sobre outros temas geralmente possuem. Essa descontração é uma marca do jornalismo esportivo. Marques de Melo (2003, p.115) cria a expressão esporte-espetáculo, pois ao lidar diretamente com a paixão das pessoas, o futebol é um meio pródigo para disseminar o sensacionalismo, no sentido de despertar sensações dos espectadores. Com a introdução da sociedade do espetáculo (DEBORD, 1997) na indústria cultural, entende-se que a mídia esportiva incorpora características da espetacularização, operando como o prolongamento de um show (OSELAME, 2012, f.81).

A brincadeira com bola é o primeiro contato do indivíduo com o esporte, ou seja, existe, numa primeira relação, um caráter lúdico. Além disso, a atividade esportiva também é recreativa, fonte de lazer. Assim, é natural que se associe o esporte com o entretenimento. No âmbito jornalístico, identificamse particularidades que se distanciam da rigidez de outras editorias. Amaral (1969, p.98) defende que, pela natureza e finalidade do jogo, o esporte é,

\footnotetext{
${ }^{5}$ Salienta-se que o conceito de esfera pública, neste caso, atende mais ao sentido de gerar uma rede de opiniões em ambiente público, como um fórum que é disponível para qualquer um participar. Habermas (2003, p.92) classifica a esfera pública como uma rede adequada para a comunicação de conteúdos, a ponto de se condensarem em opiniões públicas enfeixadas em temas específicos. Posteriormente, isto será retomado, mas a partir de outro conceito de Habermas, que se enquadra melhor no tema proposto, que é o de agir comunicativo.
}

João Pessoa - Brasil | ANO 7 VOL.7 N.1 | JAN./JUN. 2020 | p. 322-341 
sobretudo, entretenimento. Por conta do caráter lúdico e passional do jogo de futebol, retira-se o enfoque de hard-news de suas coberturas.

Lasswell e Wright (apud MARQUES DE MELO, 2003, p.112) categorizam em quatro eixos a comunicação de massa: informação, persuasão, instrução e diversão [grifo nosso]. Marques de Melo (2003, p.113) considera que o conteúdo hegemônico nas transmissões de certames desportivos se relaciona com a diversão. $O$ conceito de entretenimento vem do espanhol entretenir e significa manter no estado, que faz permanecer, durar; modernamente - e aqui, o conceito mais apropriado para a questão -, é sinônimo de divertimento, de distração (MARCONDES FILHO, 2014). O entretenimento caminha junto com o jornalismo e com os ativos da indústria cultural, como, no caso, os meios de comunicação. Embora colocado vulgarmente em um polo oposto ao jornalismo em si, verifica-se que é, na verdade, um eixo que dialoga intensamente com a prática jornalística. Por conta desta possibilidade de tratamento mais associado ao entretenimento, as emissoras de rádio mesclam em suas programações conteúdos em que o esporte é abordado com tratamento jornalístico - programas informativos - e com um tom mais descontraído - mesas-redondas. Em artigo publicado em 2018, Guimarães e Ferraretto apresentaram um levantamento sobre o percentual de ocupação de espaços dedicados ao futebol nas grades de programação das emissoras de Porto Alegre, de acordo com o quadro apresentado:

Caso haja imagens:

Quadro 1: Percentual da ocupação de espaços nas grades de ocupação das emissoras que cobrem futebol em Porto Alegre.

\begin{tabular}{|c|c|c|c|}
\hline EMISSORA $^{-}$ & SEGUNDA-SEXTA $^{\mathbf{6}}$ & SÁBADO $^{\mathbf{7}}$ & DOMINGO $^{\text {B. }}$ \\
\hline Bandeirantes & $25 \%$ & $25 \%$ & $50 \%$ \\
\hline Gaúcha & $35,4 \%$ & $25 \%$ & $56,2 \%$ \\
\hline Grenal & $100 \%$ & $100 \%$ & $100 \%$ \\
\hline Guaíba & $22,5 \%$ & $25 \%$ & $52 \%$ \\
\hline
\end{tabular}

\footnotetext{
${ }^{6}$ Entende-se como programação-base. Não computa eventual transmissão esportiva em dia de semana.

7 Em dia sem transmissão de jornada esportiva.
} 


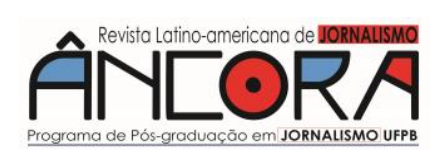

Carlos GUIMARÃES

Fonte: GUIMARÃES; FERRARETTO In: BALDISSERA; BENETTI, 2018, p. 194.

Este percentual é dividido entre programas informativos e mesasredondas. Nas rádios Grenal e Guaíba, a mesa-redonda tem duração de duas horas. Já nas rádios Bandeirantes e Gaúcha, o tempo do programa de debates é de uma hora e meia. Ou seja, há uma considerável dedicação para programas deste tipo. Há, também, uma tradição: o horário de veiculação das atrações é entre 11 e 14 horas, ou seja, no horário do almoço. Este hábito do ouvinte foi conquistado a partir da veiculação do programa Sala de Redação, pioneiro das mesas-redondas esportivas no rádio de Porto Alegre. Em 14 de junho de 1971, o programa entra na programação da Rádio Gaúcha com a proposta de, no horário do meio-dia, debater os temas relacionados ao esporte e ao jornalismo geral (GUIMARÃES, 2018, p.84-85). A atração gera um grande apelo junto ao público e consolida a hora do almoço como a hora de ouvir a falação esportiva.

O termo falação esportiva foi colocado de forma proposital para associar o modo com que a mesa-redonda se desenvolve com aquilo que Umberto Eco (1983) escreveu a respeito das coberturas esportivas. Ele argumenta que o modo com que a mídia aborda as práticas esportivas se refere muito mais ao efeito que produz junto às massas do que às preocupações e interesses que o esporte reflete na sociedade:

A falação sobre o esporte dá a ilusão de ter interesse pelo esporte,
a noção de praticar o esporte confunde-se com aquela de falar o
esporte; o falante se considera esportivo e não percebe mais que
não pratica o esporte. Desse modo, não se dá conta de que não
poderia praticá-lo, porque o trabalho que faz, quando não está
falando, o enfraquece e tira-lhe energias físicas e tempo para
praticar o esporte. Essa falação é aquela cuja função Heidegger
esboçava em Sein und Zeit: "A falação é a possibilidade de
compreender tudo sem qualquer apropriação preliminar da coisa"
[...]. E é um comportamento normal. O que importa é que se fale
(ECO, 1983, p.225).

Ao sentar-se em torno de mesa redonda, o comunicador recebe uma espécie de sentido de autoridade que lhe confere uma aura - momentânea - 
de especialista no assunto. Ao abriruma segunda tela, ou seja, ao alimentar a possibilidade de comentários em algum fórum disponível nas redes sociais, ele convida o ouvinte - que não tem a aura de especialista - para o debate, gerando a falação esportiva preconizada por Umberto Eco. Se a mesa redonda é um ambiente de debate, também é, automaticamente, um ambiente de falação. Quando se abre o recurso dos comentários de ouvintes, abre-se para a participação dos não especialistas, algo que se desmancha por conta de um papel que a audiência tem, em que o ouvinte se torna um agente comunicativo, pertencente ao espaço reservado, reprodutor das mensagens repassadas e, consequentemente, um ativo estimulador da falação esportiva.

\section{0 rádio como extensão do indivíduo e o agir comunicativo}

Goffman (2014) afirma que o indivíduo adota máscaras conforme o lugar que ele representa em diferentes ambientes sociais. Para cada situação, há um diferente comportamento, que o representa de acordo com o que ele deseja nesses distintos ecossistemas:

Dado o fato de o indivíduo efetivamente projetar uma definição da situação quando chega à presença dos outros [...], reforça-se um plano para a atividade cooperativa que se segue, conferindo-lhe um caráter promissório (GOFFMAN, 2014, p.14-16).

Ou seja, há uma representação, uma atuação - quando não encenação - que é atribuída ao indivíduo quando ele define o que fazer em determinada situação. Há, também, um sentido de projeção: além de projetar o seu comportamento no ambiente (GOFFMAN, 2010), ele se projeta de acordo com o que é produzido. No caso da mesa-redonda no rádio, do que é dito. Em sentido amplo, há uma identificação com quem compartilha as mesmas ideias do ouvinte e um sentimento de rejeição quando há a ideia contrária. Essa relação nada mais é do que idealizar a conexão que o público tem com o conteúdo transmitido a partir das relações próximas que o indivíduo tem em seu círculo social. Ele observa um programa de debates, ainda que de forma inconsciente, como um ambiente que lhe é familiar, onde a falação esportiva 


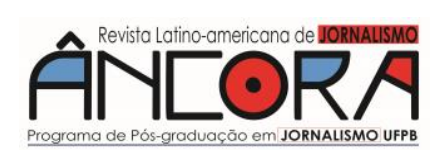

Carlos GUIMARÃES

acontece da mesma forma que ocorre em seu cotidiano. É uma extensão do seu cotidiano:

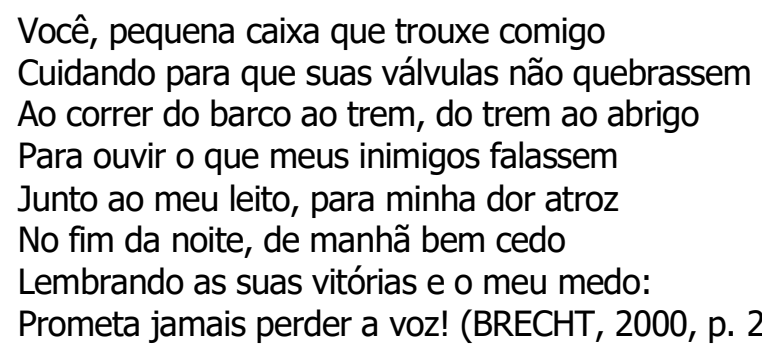

Você, pequena caixa que trouxe comigo Cuidando para que suas válvulas não quebrassem Ao correr do barco ao trem, do trem ao abrigo Para ouvir o que meus inimigos falassem Junto ao meu leito, para minha dor atroz No fim da noite, de manhã bem cedo Prometa jamais perder a voz! (BRECHT, 2000, p. 272)

Bertolt Brecht, poeta, ator, dramaturgo e ensaísta alemão, reuniu entre 1927 e 1932, cinco textos que foram compilados sob o título de "Teoria do Rádio". Sua fenomenal contribuição é vista, principalmente, em ser pioneiro ao conceber o rádio como um meio de comunicação, de propagação de informação e de função instrumental dos meios dominantes. Mas, no sentido que se pretende adotar aqui, o trecho escolhido - um poema em homenagem ao rádio - serve para dimensionar uma função do rádio que se concretizou para torná-lo, de forma efetiva, um meio de comunicação de massa: o rádio é, sobretudo, um companheiro [grifo nosso].

Marshall McLuhan (1964) enfatiza que o rádio é uma extensão dos ouvidos e do sistema nervoso central:

Num discurso pronunciado no rádio de Munique, Hitler declarou:
"Sigo o meu caminho com a segurança de um sonâmbulo. Suas
vítimas e seus críticos também apresentavam sintomas
sonambúlicos. Dançavam como que em transe, ao som do tambor
tribal do rádio, que produzia a extensão de seu sistema nervoso
central para criar um envolvimento em profundidade que atingia a
todos. "Quando ouço rádio, parece que vivo dentro dele"
(McLUHAN, 1964, p. 335).

McLuhan define o rádio como um tambor tribal, uma extensão de sentimentos e com uma potencialidade de conexão que ele classifica como uma experiência particular (McLUHAN, 1964, p.336). A transformação causada pelo meio provocou uma aceleração da informação por conta do seu imediatismo, do agora. Esse fascínio também é capaz de produzir um controle

João Pessoa - Brasil | ANO 7 VOL.7 N.1 | JAN./JUN. 2020 | p. 322-341 
sobre as massas - e daí vem a ideia de tambor tribal, onde a caixinha emite um som que desperta, faz, produz, significa. É, portanto, uma extensão em diversos sentidos: além de servir como instrumento de controle e de ser um companheiro, atua sobre aquilo que Habermas chama de agir comunicativo, em que "ação e interação não são mais vistas unicamente como produção de efeitos, mas analisadas como associadas a tramas de trocas simbólicas e contextos linguísticos". (MATELLART; MATTELART, 2014, p.144-145).

Quem também observou esse fenômeno de que as extensões não são somente sensoriais, mas de igual forma, referem-se a pertencimentos e projeções, foi Hans Magnus Enzensberger:

Pela primeira vez na história, os meios de comunicação possibilitam a participação maciça em um processo produtivo social e socializado, cujos meios práticos se encontram nas mãos das próprias massas. Uma utilização desse tipo conferiria autenticidade aos meios de comunicação (ENZENSBERGER, 1979, p. 49-50).

Enzensberger propõe, para isto, uma revisita a Brecht, que, em 1932, escreveu que a radiodifusão poderia ser um imenso sistema de canalização em que "o ouvinte não se limitasse a escutar, mas também falasse, não ficasse isolado, mas relacionado" (BRECHT In: ENZENSBERGER, 1979, p.50). Em outras palavras, a imersão do ouvinte rejeita a ideia de passividade, em que há uma emissão e ele se torna um mero receptor que não se relaciona com quem emite. É uma apropriação do meio através das percepções, dos sentidos, daquilo que McLuhan defende como uma extensão do homem.

Os sentidos atribuídos pelo rádio fornecem ideias de extensão, projeção e reprodução das mensagens, atribuindo à audiência uma sensação de pertencimento, engajamento, participação e atuação sobre e nos conteúdos disponibilizados pelo meio. A função primordial de ser um companheiro é, nesta perspectiva, transposta para uma relação imediata para aquilo que é dito, numa apropriação que leva o ouvinte para as suas relações mais próximas cotidianas. No caso da mesa-redonda esportiva, uma transcendência que o remete para a falação esportiva que, no caso, ocorre de forma simultânea ao que é dito no rádio, mas que, a partir de um ambiente como o fórum para 


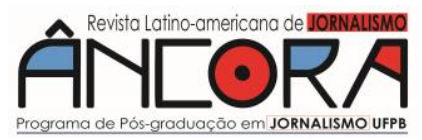

Carlos GUIMARÃES

comentários no Facebook, assume a mesma estrutura de uma conversação entre pessoas em ambiente público diante de um assunto específico, que no caso, é o futebol. O bom e velho papo de bar ${ }^{8}$.

\section{A participação dos ouvintes no Facebook durante uma mesa-redonda esportiva}

A segunda tela no rádio, isto é, a transmissão de um programa de rádio ao vivo pelo Facebook, com imagem e áudio sincronizados, nas chamadas lives, é feita pelas quatro grandes emissoras de rádio que realizam coberturas esportivas sistemáticas em Porto Alegre: Rádio Bandeirantes (94,9 FM e 640 AM), Rádio Gaúcha (93,7 FM e 600 AM), Rádio Grenal (95,9 FM) e Rádio Guaíba (101,3 FM e 720 AM). As quatro emissoras possuem um programa de debates esportivos no horário do almoço: Dupla em Debate (Rádio Grenal, 12h); Ganhando o Jogo (Rádio Guaíba, 11h); Sala de Redação(Rádio Gaúcha, 13h) e Toque de Bola (Rádio Bandeirantes, 12h).

A proposta é analisar de que forma se dá o uso desta segunda tela pelo ouvinte, com a hipótese de que ela funciona como uma extensão do que é dito no ar. A utilização da análise de conteúdo, de acordo com Bardin (2016), contribui para o processo de uma categorização proposta. A autora francesa guia o procedimento metodológico da seguinte forma:

a) organização da análise: para contemplar o objetivo (analisar o comportamento dos ouvintes de quatro programas de mesa redonda no rádio esportivo de Porto Alegre a partir de suas participações nos fóruns do Facebook), fez-se uma pré-análise, que, para Bardin (2016, p.125), é o

\footnotetext{
${ }^{8} \mathrm{O}$ bar funciona aqui como uma metáfora para os espaços sociais cotidianos do público. O bar pode ser, num ambiente contemporâneo, um grupo de WhatsApp, por exemplo. Pode ser um jantar de família, o intervalo do trabalho, o puxar assunto na fila do banco. Ambientes onde o futebol, ou melhor, a "falação esportiva" é propagada, como um pano de fundo para as conversas triviais ou mesmo para servir como elo de aproximação entre indivíduos. Aponta-se para aquilo que Damatta (1982) considera como o futebol sendo parte da sociedade, uma verdadeira expressão social que participa do cotidiano brasileiro.
}

João Pessoa - Brasil | ANO 7 VOL.7 N.1 | JAN./JUN. 2020 | p. 322-341 
planejamento das operações, isto é, definiu-se o corpus e, com isto, obtevese contato com o material.

b) definição do corpus: os principais programas de debate esportivo no formato de mesa-redonda, que ocorrem em horários similares, por volta do meio-dia, com o mesmo fluxo de audiência e com o mesmo público-alvo. Os programas escolhidos possuem a mesma característica em termos de dinâmica, tempo de duração aproximado e estilo de condução da apresentação e debatedores. $O$ da escolhido foi 26 de novembro de 2019, por atender a alguns requisitos: não foram programas que ocorreram logo após a realização de uma rodada do Campeonato Brasileiro, onde poderia haver uma interferência que distorcesse a média das interações; não foram programas no dia de um jogo importante da Dupla Grenal, onde também poderia haver algum tipo de mudança; e, por fim, não foram programas que aconteceram diante de algum fato extraordinário, como uma nova notícia ou um fato importante. A escolha do corpus se deu, portanto, pelo fato de que os programas foram veiculados de forma ordinária, isto é, sem que houvesse qualquer acontecimento fora da rotina. O resultado é obtido através de uma análise sobre a rotina dos programas, algo que foi obtido pela coleta dos dados do dia escolhido.

c) Codificação do conteúdo: o recorte apontou apenas os comentários que foram colocados no fórum. Outras possibilidades de interação, como curtidas $^{9}$ e emotions $^{10}$ foram descartadas. A codificação, portanto, corresponde na transformação dos dados brutos do texto, transformação esta que, por recorte, agregação e enumeração, permite atingir uma representação do conteúdo ou da sua expressão (BARDIN, 2016, p.134).

d) Categorização do conteúdo: houve uma separação em quatro categorias, que representam as interações básicas dos ouvintes dentro do

\footnotetext{
${ }^{9}$ Curtida, na linguagem do Facebook, significa uma simples manifestação que ocorre através de um botão representado por um polegar estendido, como se fosse um sinal de positivo. Significa, geralmente, apoio. Em alguns casos, pode ser um sinal de ironia.

10 Sinais gráficos que representam uma aprovação ou uma reprovação por parte de quem está participando, como um sorriso, um deboche ou um rosto triste.
} 


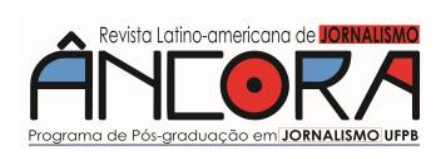

Carlos GUIMARÃES

fórum. São elas o registro de audiência, quando o ouvinte se manifesta para registrar aos comunicadores que está ouvindo o programa; a repercussão do que é dito, quando o ouvinte dá uma resposta ao comunicador, proferindo uma opinião ou propondo uma reflexão; a geração de novo conteúdo, quando se abre um novo debate no programa dentro do fórum de comentários, ou seja, paralelo ao desenvolvimento do que está no ar; e outras finalidades, que pode ser a reclamação sobre alguma questão técnica, a divulgação de alguma utilidade pública, a promoção de algum evento ou algum assunto que não tem nenhuma relação com o conteúdo apresentado pelos comunicadores.

Os resultados serão obtidos a partir destas quatro categorizações, que foram propostas por entender que os comentários encontravam, de certa forma, padrões dentro destes quatro níveis, obedecendo o recorte estipulado, com análise na segunda tela, que é, no caso, o fórum do Facebook. Realizados estes processos da análise, os resultados obtidos serão apresentados no último momento da pesquisa, a conclusão, onde serão apresentadas as inferências, que Bardin (2016, p.169) trata como uma análise de conteúdo sobre uma análise de conteúdo. Ou seja, trata-se do resultado da pesquisa, a fim de dar significação ao objeto estudado.

\section{Análise 1 - Programa Dupla em Debate, da Rádio Grenal}

Horário de veiculação: $12 \mathrm{~h}$ às $14 \mathrm{~h}$

Participantes da mesa-redonda: Ana Aguiar, Ben-Hur Marchiori, Flávio

Dal Pizzol, Kenny Braga, Roberto Pato Moure e Rogério Böhlke.

Número de visualizações - 3.989

Número de comentários - 576

Tempo de atividade da tela - 2:00:25

Quadro de categorização:

João Pessoa - Brasil | ANO 7 VOL.7 N.1 | JAN./JUN. 2020 | p. 322-341 
Quadro 2: Categorização dos comentários no fórum do Facebook da Rádio Grenal durante a transmissão do programa Dupla em Debate (RÁDIO GRENAL, 2019, 26.nov.2019).

\begin{tabular}{|c|c|c|}
\hline CATEGORIA & $\begin{array}{l}\text { QUANTIDADE } \\
\text { (TOTAL - 576) }\end{array}$ & EXEMPLO DE COMENTÁRIO ${ }^{11}$ \\
\hline $\begin{array}{l}\text { Registro de } \\
\text { audiência }\end{array}$ & 141 & $\begin{array}{l}\text { Grande Rogério abraço Abaeté azenha } \\
\text { está ligado na grenal eladio Cláudio } \\
\text { Fabiano Romarinho e Alexandre e Jessica } \\
\text { aquele abraço }\end{array}$ \\
\hline Repercussão & 376 & $\begin{array}{l}\text { O Goleiro Remi ficou anos e anos na } \\
\text { reserva do grêmio barrando os goleiros da } \\
\text { base, agora não aproveitam ninguèm. }\end{array}$ \\
\hline $\begin{array}{l}\text { Novo conteúdo } \\
\text { gerado }\end{array}$ & 51 & $\begin{array}{l}\text { Ouvinte 1: Tu quer a saída do Luan, Ben } \\
\text { hur. "Pelo bem do Luan". Tu não tem que } \\
\text { querer o bem do Luan, tem que querer o } \\
\text { bem do Grêmio. E Luan já falou que no } \\
\text { Brasil só joga no Grêmio e ele tá feliz no } \\
\text { Grêmio, apesar dessa torcida chata pra } \\
\text { caralho. } \\
\text { Ouvinte 2: Eu tbm ficaria feliz ganhando } \\
1 \text { milhão por mês } \\
\text { Ouvinte 3: E pelo bem do time dele .800 } \\
\text { mil por mês pra não jogar. } \\
\text { Ouvinte } 4: \text { Eu também ficaria feliz } \\
\text { ganhando } 1 \text { milhão e jogando lá de vez } \\
\text { em quando. }\end{array}$ \\
\hline Outros & 8 & $\begin{array}{l}\text { O BRASILEIRO NÃO É OMISSO. } \\
\text { COLOCAMOS O LULADRÃO NA CADEIA!!!! }\end{array}$ \\
\hline
\end{tabular}

Fonte: autoria própria

\section{Análise 2 - Programa Ganhando o Jogo, da Rádio Guaíba}

Horário de veiculação: $11 \mathrm{~h}$ às $13 \mathrm{~h}$

Participantes da mesa-redonda: Cristiano Oliveira, Cristiano Silva, Gutieri Sanchez, José Aldo Pinheiro, Luís Magno e Orestes de Andrade.

${ }^{11}$ Comentários retirados na íntegra, que contêm eventuais erros de português e palavras de baixo calão, apresentadas aqui como forma de sintetizar de forma fidedigna o modo com que os ouvintes atuam, sem filtro e sem qualquer tipo de adaptação. 


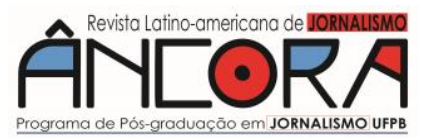

Carlos GUIMARÃES

Número de visualizações -1.720

Número de comentários - 94

Tempo de atividade da tela $-1: 54: 33$

Quadro de categorização:

Quadro 3: categorização dos comentários no fórum do Facebook da Rádio Guaíba durante a transmissão do programa Ganhando o Jogo (RÁDIO GUAÍBA, 2019, 26.nov.2019).

\begin{tabular}{|c|c|c|}
\hline CATEGORIA & $\begin{array}{l}\text { QUANTIDADE } \\
\text { (TOTAL - 94) }\end{array}$ & EXEMPLO DE COMENTÁRIO \\
\hline $\begin{array}{l}\text { Registro de } \\
\text { audiência }\end{array}$ & 12 & Boa tarde. Na escuta. \\
\hline Repercussão & 76 & $\begin{array}{l}\text { O Cássio só entrou na seleção de titular } \\
\text { por que o Marcelo e o Murriel se } \\
\text { machucaram, ele como terceiro goleiro } \\
\text { assumiu a seleção sub } 20 \text {... }\end{array}$ \\
\hline $\begin{array}{l}\text { Novo conteúdo } \\
\text { gerado }\end{array}$ & 4 & 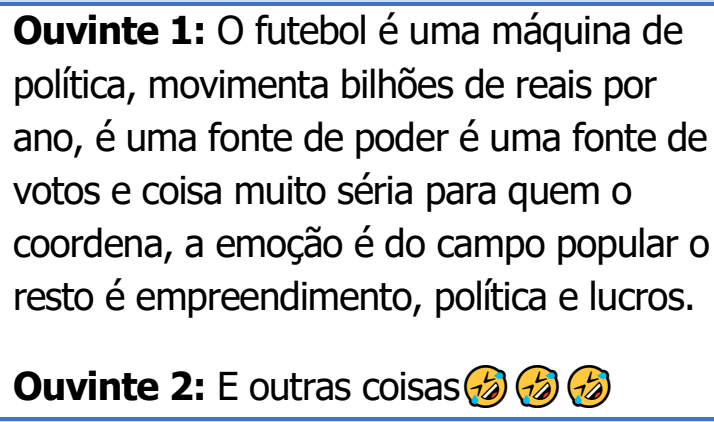 \\
\hline Outros & 2 & $\begin{array}{l}\text { O PRIMEIRO QUE IRRADIOU NOSSA } \\
\text { MÚSICA REGIONALISTA FOI ALFREDO } \\
\text { PIRAJÁ WEYER, COMPETENTE ADIALISTA. } \\
\text { NESTE DIA EM CLEVELÂNDIA, CIDADE DO } \\
\text { PARANÁ, NASCEU ESSE PIONEIRO, O } \\
\text { ALFREDO PIRAJÁ. }\end{array}$ \\
\hline
\end{tabular}

Fonte: autoria própria

\section{Análise 3 - Programa Sala de Redação, da Rádio Gaúcha}

Horário de veiculação: $13 \mathrm{~h}$ às $14 \mathrm{~h} 30$

Participantes da mesa-redonda: Adroaldo Guerra Filho, Duda Garbi, Leonardo Oliveira, Pedro Ernesto Denardin e Rafael Malenotti Número de visualizações - 35.057 
Número de comentários - 181

Tempo de atividade da tela - 29:0512

Quadro de categorização:

Quadro 4: categorização dos comentários no fórum do Facebook de GaúchaZH durante a transmissão do programa Sala de Redação (GAÚCHAZH, 2019, 26.nov.2019).

\begin{tabular}{|c|c|l|}
\hline CATEGORIA & $\begin{array}{c}\text { QUANTIDADE } \\
\text { (TOTAL - 181) }\end{array}$ & \multicolumn{1}{|c|}{ EXEMPLO DE COMENTÁRIO } \\
\hline $\begin{array}{c}\text { Registro de } \\
\text { audiência }\end{array}$ & 69 & $\begin{array}{l}\text { Pedro Ernesto que satisfação te ouvir } \\
\text { quantos Anos já faz sou lauri moraes } \\
\text { aquele trovador que viajei cm vcs uma } \\
\text { época lembra tchê um grande abraço } \\
\text { moro em Floripa SC }\end{array}$ \\
\hline Repercussão & 93 & $\begin{array}{l}\text { Everton cebolinha craque do brasileirão só } \\
\text { pode ser piada:S):-5 }\end{array}$ \\
\hline $\begin{array}{c}\text { Novo conteúdo } \\
\text { gerado }\end{array}$ & 11 & $\begin{array}{l}\text { Ouvinte 1: Arrascaeta é 1000 vezes } \\
\text { melhor que esse Cebolinha } \\
\text { Ouvinte 2: piada }\end{array}$ \\
\hline Outros & 8 & $\begin{array}{l}\text { Está a duas travando o programa Sala de } \\
\text { Redação dias travando }\end{array}$ \\
\hline
\end{tabular}

Fonte: autoria própria

\section{Análise 4 - Programa Toque de Bola, da Rádio Bandeirantes}

Horário de veiculação: $12 \mathrm{~h}$ às $14 \mathrm{~h}$

Participantes da mesa-redonda: Alex Bagé, Paulo Pires, Roberto Pauletti, Sérgio Boaz e Thaigor Janke.

Número de visualizações - 759

Número de comentários - 7

Tempo de atividade da tela - 1:55:02

Quadro de categorização:

12 A Rádio Gaúcha não transmite em sua integralidade o programa Sala de Redação no Facebook, adotando o YouTube como plataforma preferencial. Entretanto, há uma live parcial, de meia hora de programa, que foi colocada no dia 26 de novembro de 2019. Uma análise no YouTube distorceria o objeto, uma vez que a arquitetura desta rede social é diferente. Por exemplo, mesmo com 14.474 visualizações, apenas 14 comentários foram realizados. 


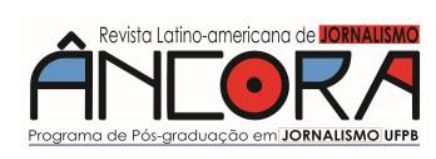

Carlos GUIMARÃES

Quadro 5: categorização dos comentários no fórum do Facebook da Rádio Bandeirantes durante a transmissão do programa Toque de Bola (RÁDIO

BANDEIRANTES, 2019, 26.nov.2019).

\begin{tabular}{|c|c|l|}
\hline CATEGORIA & $\begin{array}{c}\text { QUANTIDADE } \\
\text { (TOTAL - 7) }\end{array}$ & EXEMPLO DE COMENTÁRIO \\
\hline $\begin{array}{c}\text { Registro de } \\
\text { audiência }\end{array}$ & 2 & Boa tarde \\
\hline $\begin{array}{c}\text { Repercussão } \\
\text { Novo conteúdo } \\
\text { gerado }\end{array}$ & 5 & $\begin{array}{l}\text { Martín Campaña (Independiente) e } \\
\text { Mariano Andujar (Estudiantes) aí são } \\
\text { ótimos goleiros para o Grêmio! }\end{array}$ \\
\hline Outros & 0 & \\
\hline
\end{tabular}

Fonte: autoria própria

\section{Considerações finais}

As transformações tecnológicas determinam mudanças nas estratégias das empresas de comunicação. Com o surgimento da Internet e a possibilidade de transbordar o conteúdo para o meio digital, o rádio expandiu-se para outras mídias. Se antes a única maneira de acompanhar a programação das emissoras era através da sintonia hertziana, hoje o áudio pode ser acompanhado por imagens, textos e participação de quem não integra os programas. O formato de mesa-redonda tem uma característica que aproxima aquilo que é dito de quem escuta. A falação esportiva, expressão cunhada por Umberto Eco (1983) transcende as pessoas que transmitem o debate, gerando uma apropriação pelo usuário, ou seja, há um estímulo para que o ouvinte também participe.

Em termos de comunicação tecnológica, que remete a uma essência técnica, deu-se o nome de convergência (JENKINS, 2008) para este novo momento. Todavia, a intenção do artigo era associar esse transbordamento a questões de hábito, de atuação e de atribuir à audiência um significado de, em 
primeiro plano, pertencimento ao que é dito e, em segundo momento, de interferência e novas produções sobre o que é dito. Tais pretensões encontram em Habermas (1981) uma base teórica relevante sobre o que é o agir comunicativo, em que as redes de interação geram uma sociedade constituída por relações comunicativas (MATTELART; MATTELART, 2014, p.145). Algo que já havia sido previsto por Enzensberger (1979), não mais sobre a força que manipula a audiência, mas sobre uma força que mobiliza a audiência, instigando-a a este agir comunicativo.

Evidentemente, são desmembramentos das previsões mcluhanianas sobre o futuro dos meios de comunicação, em que a sua mera existência como difusor ou propagador torna-se obsoleta com a sua constituição de ser uma extensão humana, que gera uma produção sensorial ao consumidor. Neste sentido, torna-se imperativo buscar as primeiras teorizações sobre o rádio e as formulações de Bertolt Brecht (1927-1932), que previu de certa forma todas as funções e operações do meio rádio nos quase 100 anos seguintes. Se o rádio é um companheiro, as novas tecnologias possibilitaram "falar com essa companhia". Não um falar sozinho, não um simples pano de fundo em que o "rádio não ouve". Hoje, o rádio ouve, responde e dá ideias.

O futebol, por ter uma força lúdica e passional, estimula essa troca que para Habermas ainda era simbólica, mas que hoje é real. A mesa-redonda amplifica ainda mais a falação, conforme o termo de Eco. Por isso, a análise sobre o comportamento da audiência no ambiente de segunda tela, ou seja, nas lives de Facebook enquanto os programas são transmitidos pelo rádio, demonstrou alguns resultados que encontram a hipótese apresentada e a base teórica sugerida.

Há distorções entre o número de visualizações e o número de comentários feitos nos fóruns. Não há ainda métrica que dimensione o tempo de audiência que cada um teve ao visualizar a transmissão ao vivo. A mesma medida serve para quem assistiu ao programa por um segundo ou para quem assistiu por uma hora. Um mesmo ouvinte pode sair e voltar na transmissão, 


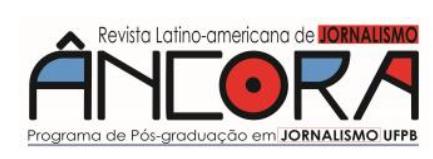

Carlos GUIMARÃES

gerando mais visualizações para uma pessoa. O índice apresenta, portanto, uma média. Evidentemente, os números de comentários são menores do que o número de visualizações. Comentar requer parar aquilo que se faz para esboçar um raciocínio e realizar um procedimento, diferentemente do hábito de ouvir, que é possível ser realizado junto com outra tarefa, simultaneamente. $\mathrm{O}$ artigo também não se propôs a medir audiência, tampouco a se debruçar a respeito de uma emissora ter muito mais pessoas assistindo que outra. $\mathrm{A}$ ilustração quantitativa foi feita para dimensionar que a estratégia de mostrar imagens dos integrantes dos programas junto à transmissão pelo rádio tem uma boa participação.

Apresentadas as explicações pertinentes ao corpus, é possível inferir que, das categorias apresentadas, a que tem mais força ainda é a repercussão do que é dito, isto é, quando ocorre a fala de um comunicador, há uma resposta do ouvinte. Ainda é grande o número de pessoas que apenas registram que estão ouvindo, para que seu nome seja falado pelo jornalista. A geração de novos debates no fórum permanece, de certa forma, tímida, mas não irrelevante. A atenção ainda é voltada mais para o comunicador do que para quem comenta. Há, também, ouvintes que utilizam o fórum para outros recados, em geral, para manifestar uma opinião política ou reclamar de algum problema técnico.

Nas interações, os ouvintes assumem um papel, como Goffman (2014) ajuizou. No caso, interpretam a função de debatedores, de audiência que pretende interferir, participar, que transcende o interagir, em muitos casos. 0 ouvinte apropria-se para si do conteúdo transmitido, podendo gerar uma nova cadeia de acontecimentos na segunda tela - como a geração de um novo debate - ou simplesmente desejar que sua participação gere uma nova cadeia na tela principal- quando o comunicador leva em consideração um comentário da audiência.

João Pessoa - Brasil | ANO 7 VOL.7 N.1 | JAN./JUN. 2020 | p. 322-341 
Portanto, é possível concluir, ainda que em uma análise exploratória inicial, com desenvolvimento para outros cenários que desdobramentos desta pesquisa poderá contemplar, que o fórum de debates do Facebook, durante a transmissão de uma mesa-redonda no rádio de Porto Alegre, constitui-se através de uma participação efetiva do público, que assume um papel semelhante ao que o comunicador tem - o papel de debatedor - e, por fim, atribui um novo sentido para o que é dito e para o que ele próprio significa com a geração de novos debates e surgimento de novas ideias. A segunda tela se torna, logo, uma extensão da primeira. Neste caso, o ouvinte se torna uma extensão do comunicador e o rádio a extensão de uma conversa que lhe soa familiar, primeiro como companhia e, em momentos mais efusivos, remetida para seus fóruns particulares e seus grupos de discussões. A segunda tela vira um grande papo de bar, com xingamentos, palavrões, apoios, revoltas, indignações e momentos em que ele precisa mais falar que ouvir.

\section{Referências}

AMARAL, Luiz. Técnica de jornal e periódico. Rio de Janeiro: Tempo Brasileiro, 1969.

BARDIN, Laurence. Análise de conteúdo. São Paulo: Edições 70, 2016.

BRECHT, Bertolt. "Ao pequeno aparelho de rádio". In: . Poemas. 1913-1956.

São Paulo: Editora 34, 2000.

CANATTA, Fábio. TV e segunda tela: Uma análise do horário nobre no Twitter. 2014. Dissertação (Mestrado em Comunicação Social) - Curso de Pós Graduação em Comunicação, Faculdade de Comunicação Social, PUCRS, Porto Alegre, 2014. DAMATTA, Roberto e outros. Universo do futebol: Esporte e sociedade brasileira. Rio de Janeiro: Pinakotheke, 1982.

DEBORD, Guy. A sociedade do espetáculo. Rio de Janeiro: Contraponto, 2017. ECO, Umberto. Viagem na irrealidade cotidiana. Rio de Janeiro: Nova Fronteira, 1984.

ENZENSBERGER, Hans Magnus. Elementos para uma teoria dos meios de comunicação. Rio de Janeiro: Tempo Brasileiro, 1979.

ESPORTE BAND RS. "Toque de Bola na rádio Bandeirantes". Facebook: EsporteBandRS. 26.nov.2019. Disponível em: <https://www.facebook.com/EsporteBandRS/videos/489830625214353/> Acesso em 29.nov.2019

FERRARETTO, Luiz Artur. Uma proposta de periodização para a história do rádio no Brasil. Eptic - Revista de Economia Política das Tecnologias da Informação e Comunicação, Aracaju: Observatório de Economia e Comunicação da Universidade Federal do Sergipe, v. XIV, n. 2, maio-ago. 2012.

FERRARETTO, Luiz Artur. Rádio: Teoria e prática. São Paulo: Summus, 2014. 
